Research Article

\title{
Free Vibration of Composite Cylindrical Shells Based on Third-Order Shear Deformation Theory
}

\author{
Muneerah Saad AL Nuwairan (D) and Saira Javed (i) \\ Department of Mathematics and Statistics, College of Science, King Faisal University, P.O. Box 400, Al ahsa 31982, Saudi Arabia \\ Correspondence should be addressed to Saira Javed; sulhaque@kfu.edu.sa
}

Received 15 October 2021; Revised 28 November 2021; Accepted 6 December 2021; Published 30 December 2021

Academic Editor: Kenan Yildirim

Copyright (C) 2021 Muneerah Saad AL Nuwairan and Saira Javed. This is an open access article distributed under the Creative Commons Attribution License, which permits unrestricted use, distribution, and reproduction in any medium, provided the original work is properly cited.

\begin{abstract}
The focus of this study is to analyse the free vibration of cylindrical shells under third-order shear deformation theory (TSDT). The constitutive equations of the cylindrical shells are obtained using third-order shear deformation theory (TSDT). The surface and traverse displacements are expected to have cubic and quadratic variation. Spline approximation is used to approximate the displacements and transverse rotations. The resulting generalized eigenvalue problem is solved for the frequency parameter to get as many eigenfrequencies as required starting from the least. From the eigenvectors, the spline coefficients are computed from which the mode shapes are constructed. The frequency of cylindrical shells is analysed by varying circumferential node number, length dimension, layer number, and different materials. The authenticity of the present formulation is established by comparing with the available FEM results.
\end{abstract}

\section{Introduction}

Composite shell structures are source of attraction for marine structures such as submarines [1-6]. Stability of these structures depends upon thickness of shells, materials used, lamination scheme, and ply orientation. The multilayered structures are analysed using classical and shear deformation theories [7-9]. Thin structures have ratio of thickness equal to $1 / 20$ or less and are studied using classical bending theory; however, structures with the ratio greater than $1 / 20$ are examined by shear deformation theories. Love [10] proposed the shell's classical theory, whereas Naghdi [11] included the shear deformations in kinematics of the shells. In addition, Reddy [12] developed a simple SDT for layered plates, and a simple SDT for layered shells was developed by Reddy and Liu [13]. To avoid the discrepancies of the FSDT, HSDT was developed to precisely estimate the crosswise shear stresses which are significant in thick plates and shells. iHSDT plate theories suggest the expansion of displacements to required degree with respect to thickness coordinates avoiding a shear correction factor (see Vinson [14] and Noor et al. [15]). Further, HSDT calculates more precise interlaminar stress distributions and fulfills the requirements that there are no shear stresses at the top and bottom of the shell surfaces. In TSDT, the displacements are extended to the power of three so that to get crosswise shear stresses and strains variation of fourth power through thickness. This neglects the requirement of shear correction coefficient [16].

Different methods incorporating HSDT were adopted by different researchers for analysing free vibration of shells. Among them, Baghlani et al. [17] used Fourier series to examine the free vibration of FGM cylindrical shells, Dehsaraji et al. [18] used the Navier method to analyse free vibration of FG nanoshells, moreover, Sayyad and Ghugal [19] used Navier technique to analyse composite spherical shells, and Rout et al. [20] analysed thermoelastic unrestricted vibration of the multilayered shells considering the Green-Lagrange type of nonlinearity. HSDT along with Navier solutions was used to examine the vibration of shells and plates by Zine et al. [21]. Newton-Raphson iterative technique was used to analyse geometrical nonlinear bending characteristics of shells by Chavan and Lal [22] based on HSDT and Green-Lagrange nonlinearity. FEM was 
used to observe the unrestricted vibration of FG shells under HSDT (see Zghal et al. [23]). Nonlinear vibration of the layered shells was studied by Hirwani et al. [24] using Fourier transform technique based on HSDT. The Chebyshev-Ritz method was adopted to study the vibration of FG layered beams for HSDT by Shenas et al. [25]. The unrestricted vibration of FG carbon nanotube layered quadrilateral spherical panels was studied using HSDT with DQM by Setoodeh et al. [26]. Frequency variation based on sound radiation of doubly curved layered composite shells was examined by Sharma et al. [27] using HSDT and FEM. The HSDT incorporating with the discrete method was used to study curved structural parts [28]. The Navier method based on HSDT was used by Punera and Kant [29] to investigate FG cylindrical shells. HSDT was used by Hwu et al. [30] to examine the vibration of layered plates and cylindrical shells. Moreover, HSDT and GM were used by Nasihatgozar et al. [31] to analyse the free vibration of doubly curved sheets. Nguyen et al. [32] examined the vibration of functionally graded plates using HSDT. Moreover, nanoplates in the thermal environment were studied by Diakh et al. [33]. Baghlani et al. [34] investigated the free vibration of FGM cylindrical shells on elastic foundation. The FEM method was used to study the free and static vibration of FGM plates by Katili [35]. Cross-ply laminates were studied by Dhari and Singh [36]. Higher-order shear deformation theories with the unified model were studied for composite plates by Li et al. [37]. HSDT was used to analyse wave propagation of a ceramic-metal functionally graded sandwich plates by Tahir et al. [38]. Moreover, hygro-thermo-mechanical bending behavior of advanced functionally graded ceramicmetal plate was studied by Mudhaffar et al. [39]. An original four-variable quasi-3D shear deformation theory for the static and free vibration analysis of new type of sandwich plates was studied by Kouider et al. [40]. Merazka et al. [41] examined the hygro-thermo-mechanical bending response of FG plates. Bending analysis of functionally graded plates was investigated by Hachemi et al. [42].

The individuality of the current study is evident that none of the abovementioned researchers used spline approximation to analyse the free vibrational problems except Javed et al. [43]. Moreover, Javed et al. [43] used the spline approximation method to analyse the free vibration of plates whereas in this research spline approximation is used to analyse composite cylindrical shells. In addition to that stress-strain relation of plates and cylindrical shells is different so derivation of equilibrium equation was completely different as compared with Javed et al. [43]. Therefore, current investigation aims to analyse the free vibration of composite cylindrical shells. Spline approximation is used to approximate the displacement and rotational functions. Resulting equations along with the end condition equations obtain a system of equations. The frequency parameter is obtained using eigen solution technique. The mode shapes are created using eigenvector. Cylindrical shells are investigated by varying their lengths, layer sequence, layer constituents, and circumferential node number. Results are depicted using graphs and tables. Autocad software is used to draw some figures.

\section{Formulation and Method}

A composite laminated circular cylindrical shell of having length $\ell$, thickness $h$, and radius $r$ is shown in Figure 1. The $x$ coordinate of the shell $s$ is taken along the longitudinal direction, $\theta$ coordinate along the circumferential direction, and $z$ along the thickness direction.

2.1. Displacement Equations. The displacement field is based on TSDT (see Reddy [16]):

$u(x, y, z, t)=u_{0}(x, y, t)+z \phi_{x}(x, y, t)-\frac{4 z^{3}}{3 h^{2}}\left(\phi_{x}+\frac{\partial w_{0}}{\partial x}\right)$,
$v(x, y, z, t)=v_{0}(x, y, t)+z \phi_{\theta}(x, y, t)-\frac{4 z^{3}}{3 h^{2}}\left(\phi_{\theta}+\frac{\partial w_{0}}{\partial y}\right)$,

$w(x, y, z, t)=w_{0}(x, y, t)$

where $u, v$, and $w$ are the displacement functions in $x, \theta$, and $z$ directions, respectively, $u_{0}, v_{0}$, and $w_{0}$ are the displacements of the middle surface of the cone, and $\psi_{x}$ and $\psi_{\theta}$ are shear rotations of any point on the middle surface.

2.2. Constitutive Equations. Stress, moment, and shear resultants $N, M$, and $Q$ and higher-order stress resultants $P$ and $R$ are defined as

$$
\begin{aligned}
& \left\{\begin{array}{c}
N_{x} \\
N_{\theta} \\
N_{x \theta} \\
M_{x} \\
M_{\theta} \\
M_{x \theta} \\
P_{x} \\
P_{\theta} \\
P_{x \theta}
\end{array}\right\}=\int_{-h / 2}^{h / 2}\left\{\begin{array}{c}
\sigma_{x} \\
\sigma_{\theta} \\
\sigma_{x \theta} \\
z \sigma_{x} \\
z \sigma_{\theta} \\
z \sigma_{x \theta} \\
z^{3} \sigma_{x} \\
z^{3} \sigma_{\theta} \\
z^{3} \sigma_{x \theta}
\end{array}\right\} \mathrm{d} z, \\
& \left\{\begin{array}{c}
Q_{\theta} \\
Q_{x} \\
R_{\theta} \\
R_{x}
\end{array}\right\}=\int_{-h / 2}^{h / 2}\left\{\begin{array}{c}
\tau_{\theta z} \\
\tau_{x z} \\
z^{2} \tau_{\theta z} \\
z^{2} \tau_{x z}
\end{array}\right\} \mathrm{d} z,
\end{aligned}
$$

where $\sigma_{i}$ is the normal stress and $\tau_{i}$ is the shear stress components.

The transformed stress-strain relations are as follows: 


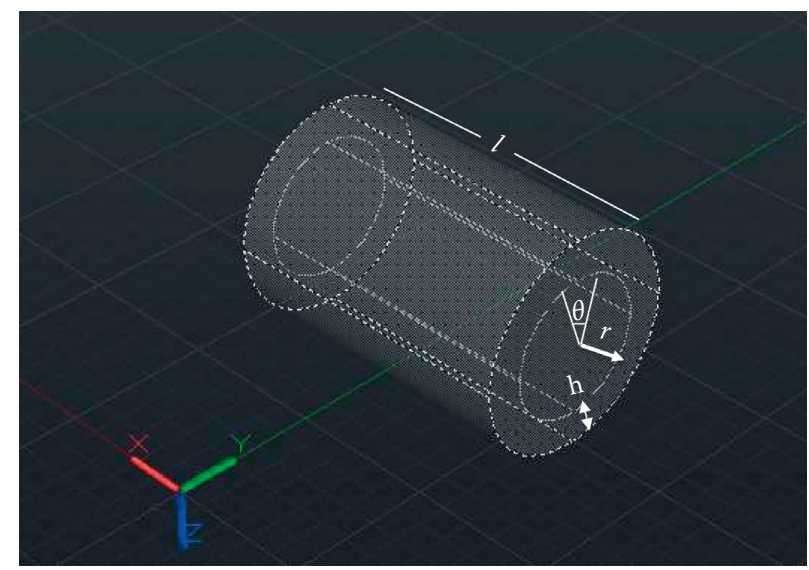

Figure 1: Cylindrical shell (geometry).

$$
\left(\begin{array}{c}
\sigma_{x}^{(k)} \\
\sigma_{\theta}^{(k)} \\
\tau_{x \theta}^{(k)} \\
\tau_{\theta z}^{(k)} \\
\tau_{x z}^{(k)}
\end{array}\right)=\left(\begin{array}{ccccc}
Q_{11}^{(k)} & Q_{12}^{(k)} & Q_{16}^{(k)} & 0 & 0 \\
Q_{12}^{(k)} & Q_{22}^{(k)} & Q_{26}^{(k)} & 0 & 0 \\
Q_{16}^{(k)} & Q_{26}^{(k)} & Q_{66}^{(k)} & 0 & 0 \\
0 & 0 & 0 & Q_{44}^{(k)} & Q_{45}^{(k)} \\
0 & 0 & 0 & Q_{45}^{(k)} & Q_{55}^{(k)}
\end{array}\right)\left(\begin{array}{c}
\varepsilon_{x}^{(k)} \\
\varepsilon_{\theta}^{(k)} \\
\gamma_{x \theta}^{(k)} \\
\gamma_{\theta z}^{(k)} \\
\gamma_{x z}^{(k)}
\end{array}\right),
$$

where $Q_{i j}{ }^{(k)}$ are given in Appendix A.

The stress-strain relations are obtained as follows:

$$
\begin{aligned}
& \left\{\begin{array}{c}
N_{x} \\
N_{\theta} \\
N_{x \theta} \\
M_{x} \\
M_{\theta} \\
M_{x \theta} \\
P_{x} \\
P_{\theta} \\
P_{x \theta}
\end{array}\right\}=\left(\begin{array}{lllllllll}
A_{11} & A_{12} & A_{16} & B_{11} & B_{12} & B_{16} & E_{11} & E_{12} & E_{16} \\
A_{12} & A_{22} & A_{26} & B_{12} & B_{22} & B_{26} & E_{12} & E_{22} & E_{26} \\
A_{16} & A_{26} & A_{66} & B_{16} & B_{26} & B_{66} & E_{16} & E_{26} & E_{66} \\
B_{11} & B_{12} & B_{16} & D_{11} & D_{12} & D_{16} & F_{11} & F_{12} & F_{16} \\
B_{12} & B_{22} & B_{26} & D_{12} & D_{22} & D_{26} & F_{12} & F_{22} & F_{26} \\
B_{16} & B_{26} & B_{66} & D_{16} & D_{26} & D_{66} & F_{16} & F_{26} & F_{66} \\
E_{11} & E_{12} & E_{16} & F_{11} & F_{12} & F_{16} & H_{11} & H_{12} & H_{16} \\
E_{12} & E_{22} & E_{26} & F_{12} & F_{22} & F_{26} & H_{12} & H_{22} & H_{26} \\
E_{16} & E_{26} & E_{66} & F_{16} & F_{26} & F_{66} & H_{16} & H_{26} & H_{66}
\end{array}\right)\left\{\begin{array}{c}
\varepsilon_{x}^{(0)} \\
\varepsilon_{\theta}^{(0)} \\
\gamma_{x \theta}^{(0)} \\
\varepsilon_{x}^{(1)} \\
\varepsilon_{\theta}^{(1)} \\
\gamma_{x \theta}^{(1)} \\
\varepsilon_{x}^{(3)} \\
\varepsilon_{\theta}^{(3)} \\
\gamma_{x \theta}^{(3)}
\end{array}\right\}, \\
& \left\{\begin{array}{c}
Q_{\theta} \\
Q_{x} \\
R_{\theta} \\
R_{x}
\end{array}\right\}=\left(\begin{array}{llll}
A_{44} & A_{45} & D_{44} & D_{45} \\
A_{45} & A_{55} & D_{45} & D_{55} \\
D_{44} & D_{45} & F_{44} & F_{45} \\
D_{45} & D_{55} & F_{45} & F_{55}
\end{array}\right)\left\{\begin{array}{c}
\gamma_{\theta z}^{(0)} \\
\gamma_{x z}^{(0)} \\
\gamma_{\theta z}^{(2)} \\
\gamma_{x z}^{(2)}
\end{array}\right\},
\end{aligned}
$$

where $\varepsilon$ is the strain and $\gamma$ is the shear strain components. 
Stiffness coefficients $A_{i j}, B_{i j}$, and $D_{i j}$ (extensional, bending-extensional coupling, and bending stiffnesses) and $E_{i j}, F_{i j}$, and $H_{i j}$ are the higher-order stiffness coefficients defined in Appendix B.
2.3. Cylindrical Shell Equations. The equilibrium equations for cylindrical shells based on TSDT are as follows:

$$
\begin{aligned}
& \frac{\partial N_{x}}{\partial x}+\frac{1}{r} \frac{\partial N_{x \theta}}{\partial \theta}=I_{0} \frac{\partial^{2} u}{\partial t^{2}}+\left(I_{1}-c_{1} I_{3}\right) \frac{\partial^{2} \phi_{x}}{\partial t^{2}}-c_{1} I_{3} \frac{\partial^{3} w}{\partial x \partial t^{2}} \\
& \frac{\partial N_{x \theta}}{\partial x}+\frac{1}{r} \frac{\partial N_{\theta}}{\partial \theta}+\frac{1}{r} Q_{\theta}=\left(I_{0}+\frac{2}{r} I_{1}\right) \frac{\partial^{2} v}{\partial t^{2}}+\left(I_{1}+\frac{1}{r} I_{2}-c_{1} I_{3}-c_{1} \frac{1}{r} I_{4}\right) \frac{\partial^{2} \phi_{\theta}}{\partial t^{2}} \\
& -\left(c_{1} I_{3}+c_{1} \frac{1}{r} I_{4}\right) \frac{\partial^{3} w}{\partial \theta \partial t^{2}} \\
& \frac{\partial \bar{Q}_{x}}{\partial x}+\frac{1}{r} \frac{\partial \bar{Q}_{\theta}}{\partial \theta}-\frac{1}{r} N_{\theta}+c_{2}\left(\frac{\partial^{2} P_{x}}{\partial x^{2}}+2 \frac{1}{r} \frac{\partial^{2} P_{x \theta}}{\partial x \partial \theta}+\frac{1}{r^{2}} \frac{\partial^{2} P_{\theta}}{\partial \theta^{2}}\right)=c_{1} I_{3} \frac{\partial^{3} u}{\partial x \partial t^{2}}+\left(c_{1} I_{3}+\frac{c_{1}}{r} I_{4}\right) \frac{\partial^{3} v}{\partial \theta \partial t^{2}}+I_{0} \frac{\partial^{2} w}{\partial t^{2}}-c_{1}^{2} I_{6}\left(\frac{\partial^{4} w}{\partial x^{2} \partial t^{2}}+\frac{\partial^{4} w}{\partial \theta^{2} \partial t^{2}}\right) \\
& +\left(c_{1} I_{4}-c_{1}^{2} I_{6}\right) \frac{\partial^{3} \phi_{x}}{\partial x \partial t^{2}}+\left(c_{1} I_{4}-c_{1}^{2} I_{6}\right) \frac{\partial^{3} \phi_{\theta}}{\partial \theta \partial t^{2}} \\
& \frac{\partial \bar{M}_{x}}{\partial x}+\frac{1}{r} \frac{\partial \bar{M}_{x \theta}}{\partial \theta}-\bar{Q}_{x}=\left(I_{1}-c_{1} I_{3}\right) \frac{\partial^{2} u}{\partial t^{2}}-\left(c_{1} I_{4}-c_{1}^{2} I_{6}\right) \frac{\partial^{3} w}{\partial x \partial t^{2}}+\left(I_{2}-2 c_{1} I_{4}+c_{1}^{2} I_{6}\right) \frac{\partial^{2} \phi_{x}}{\partial t^{2}}, \\
& \frac{\partial \bar{M}_{x \theta}}{\partial x}+\frac{1}{r} \frac{\partial \bar{M}_{\theta}}{\partial \theta}-\bar{Q}_{\theta}=\left(I_{1}+\frac{1}{r} I_{2}-c_{1} I_{3}-c_{1} \frac{1}{r} I_{4}\right) \frac{\partial^{2} v}{\partial t^{2}}-\left(c_{1} I_{4}-c_{1}^{2} I_{6}\right) \frac{\partial^{3} w}{\partial \theta \partial t^{2}} \\
& +\left(I_{2}-2 c_{1} I_{4}+c_{1}^{2} I_{6}\right) \frac{\partial^{2} \phi_{\theta}}{\partial t^{2}} \\
& X=\frac{x}{l}, \text { a distant coordinate, and } X \in[0,1] \text {; }
\end{aligned}
$$

$$
\begin{aligned}
& c_{1}=\frac{4}{h^{2}}, c_{2}=\frac{c_{1}}{3}, \\
& I_{i}=\int_{z} \rho^{(k)}(z) \mathrm{d} z, \quad(i=0,1,2,3, \ldots, 6),
\end{aligned}
$$

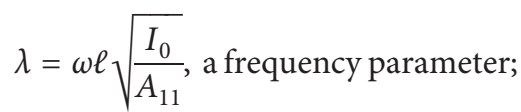

$L=\frac{\ell}{r}$, a length parameter,

and $\rho$ is the material density of the $k$-th layer. $\bar{M}_{x}=M_{x}-c_{1} P_{x}, \quad \bar{M}_{\theta}=M_{\theta}-c_{1} P_{\theta}, \quad$ and $\quad \bar{M}_{x \theta}=$ $M_{x \theta}-c_{1} P_{x \theta}$ :

$$
\begin{aligned}
& \bar{Q}_{\theta}=Q_{\theta}-c_{2} R_{\theta}, \\
& \bar{Q}_{x}=Q_{x}-c_{2} R_{x},
\end{aligned}
$$

where $N_{i}, M_{i}$, and $Q_{i}$ are stress, moment, and shear resultants, respectively. $P_{i}$ and $R_{i}$ denote higher-order stress resultants.

Firstly, stress and strain relations are substituted in equation (5). After that the displacements and rotational functions for shells [44] are used, and resulting differential equation was nondimensionalized by using following parameters:

$H=\frac{h}{r}$, ratio of total thickness to radius; $\delta_{k}=\frac{h_{k}}{h}$, relative layer thickness of the $k-$ th layer.

Nondimensional equation is obtained in the matrix form as

$$
\left[\begin{array}{ccccc}
Y_{11} & Y_{12} & Y_{13} & Y_{14} & Y_{15} \\
Y_{21} & Y_{22} & Y_{23} & Y_{24} & Y_{25} \\
Y_{31} & Y_{32} & Y_{33} & Y_{34} & Y_{35} \\
Y_{41} & Y_{42} & Y_{43} & Y_{44} & Y_{45} \\
Y_{51} & Y_{52} & Y_{53} & Y_{54} & Y_{55}
\end{array}\right]\left\{\begin{array}{c}
U \\
V \\
W \\
\Phi_{X} \\
\Phi_{\theta}
\end{array}\right\}=\left\{\begin{array}{l}
0 \\
0 \\
0 \\
0 \\
0
\end{array}\right\},
$$




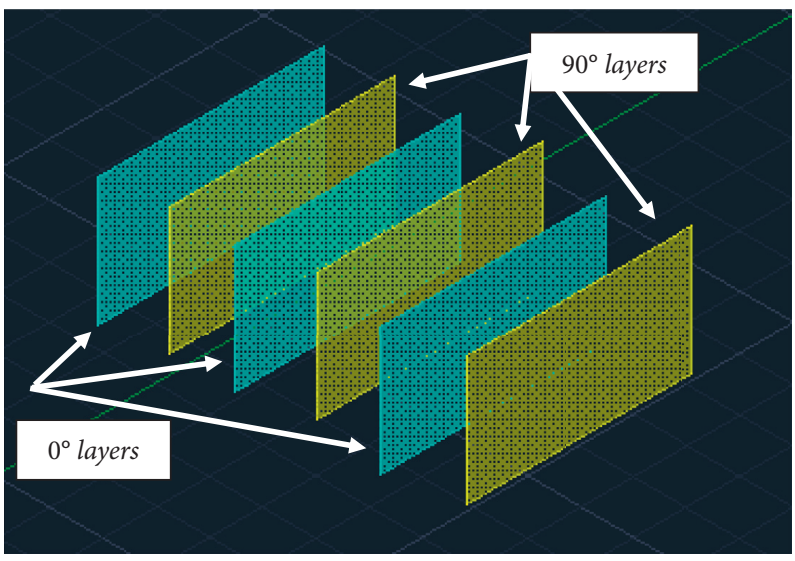

Figure 2: Composite with six layers.

where differential operators $Y_{i j}^{\prime} s$ are given in Appendix C.

2.4. Spline Method. Equation (9) consists of $U(X)$ derivatives of order three, $V(X)$ derivatives of order two, $W(X)$ derivatives of order four, $\Phi_{X}(X)$ derivatives of order three, and $\Phi_{\theta}(X)$ derivatives of order two. These functions are approximated by using cubic and quintic spline functions, in the range of $X \varepsilon[0,1]$.

The displacement functions $U(X), V(X)$, and $W(X)$ and the rotational functions $\Phi_{X}(X)$ and $\Phi_{\theta}(X)$ are approximated by

$$
\begin{aligned}
U(X) & =\sum_{i=0}^{4} a_{i} X^{i}+\sum_{j=0}^{N-1} b_{j}\left(X-X_{j}\right)^{5} H\left(X-X_{j}\right), V(X)=\sum_{i=0}^{2} c_{i} X^{i}+\sum_{j=0}^{N-1} d_{j}\left(X-X_{j}\right)^{3} H\left(X-X_{j}\right), \\
W(X) & =\sum_{i=0}^{4} e_{i} X^{i}+\sum_{j=0}^{N-1} f_{j}\left(X-X_{j}\right)^{5} H\left(X-X_{j}\right), \Phi_{X}(X)=\sum_{i=0}^{4} g_{i} X^{i}+\sum_{j=0}^{N-1} g_{j}\left(X-X_{j}\right)^{5} H\left(X-X_{j}\right), \\
\Phi_{\Theta}(X) & =\sum_{i=0}^{2} l_{i} X^{i}+\sum_{j=0}^{N-1} q_{j}\left(X-X_{j}\right)^{3} H\left(X-X_{j}\right) .
\end{aligned}
$$

Here, $H\left(X-X_{j}\right)$ is the Heaviside step function and $N$ is the number of intervals into which the range $[0,1]$ of $X$ is divided. The points $X=X_{s}=(s / N)(s=0,1,2, \ldots, N)$ are selected as the spline knots. Therefore, differential equation (9) is satisfied by the spline, at all $X_{s}$. The resulting expressions contain $(5 N+5)$ homogeneous system of equations in the $(5 N+21)$ spline coefficients. The S-S boundary condition is considered in order to coincide the number of equations and unknowns.

\section{Results and Discussion}

The vibrational response of cylinderical shells under S-S end condition is analysed. Cylindrical shells of cross-ply orientations of two, three, four, five, and six layers are considered. Figure 2 shows 6-layered composite with cross-ply orientation.

Comparative study can be seen in Table 1 with Khare et al. [45] (using FSDT and HSDT) and Bhimaraddi [46] (using constant shear deformation theory and thin shell theory) for orthotropic two-layer cross-ply S-S cylindrical shells.

Table 2 shows the relation between the angular frequency parameter and length of 2-layered cylindrical shells $\omega_{m}$ and length of 2-layered cylindrical shells. There is the inverse relation between the angular frequency and length whereas there is a positive relation between frequency and mode number.

Table 3 depicts the relation between frequency parameter $\lambda_{m}$ and circumferential node number $n$ for three $0^{0} / 90^{\circ} / 0^{\circ}(G E / K E / G E)$ and six layered cylindrical shells $0^{0} / 90^{\circ} / 0^{\circ} / 90^{\circ} / 0^{\circ} / 90^{\circ}(G E / K E / G E / K E / G E / K E)$. The length is considered to be $L=1.5$. The frequency declines till $n=5$ and slightly rises afterward.

Figures 3-5 demonstrate the effect of length on the angular frequency parameter of 3-, 4-, and 5-layered cylindrical shells with the fixed $n=2$. The frequency declines till $L=1$ and remains same afterward. This is because that the membrane longitudinal strain dominates the total strain energy of the system till length of the shell is 1 . However, as 
TABLE 1: The value of frequency parameter $\lambda=\omega \ell \sqrt{\left(I_{0} / A_{11}\right)}$ of two-layered orthotropic shells under S-S boundary conditions is compared with Khare et al. [45] $\bar{\omega}=\omega a /\left(\rho / E_{2}\right)^{1 / 2}$ and Bhimaraddi [46].

\begin{tabular}{|c|c|c|c|c|c|c|}
\hline \multirow[t]{2}{*}{$L$} & \multirow[t]{2}{*}{$H$} & \multirow{2}{*}{$\begin{array}{c}\text { Present } \\
\text { HSDT }\end{array}$} & \multicolumn{2}{|c|}{ Khare et al. [45] } & \multicolumn{2}{|c|}{ Bhimaraddi [46] } \\
\hline & & & FOST & HOST & PSD & CSD \\
\hline \multirow[t]{3}{*}{1} & 0.05 & 0.77214 & 0.78567 & 0.78627 & 0.79993 & 0.79798 \\
\hline & 0.10 & 1.03241 & 1.04062 & 1.04357 & 1.09189 & 1.07475 \\
\hline & 0.15 & 1.28216 & 1.29578 & 1.30351 & 1.38174 & 1.33274 \\
\hline \multirow[t]{3}{*}{2} & 0.05 & 0.55132 & 0.56568 & 0.56684 & 0.58000 & 0.57733 \\
\hline & 0.10 & 0.91734 & 0.91367 & 0.91801 & 0.95664 & 0.93653 \\
\hline & 0.15 & 1.22513 & 1.22101 & 1.23107 & 1.28933 & 1.23527 \\
\hline
\end{tabular}

TAвLE 2: Relation between angular frequency $\omega_{m}$ and length $L$ of two-layered $0^{0} / 90^{0}$ cylindrical shell $n=2$.

\begin{tabular}{|c|c|c|c|c|c|c|}
\hline \multirow{2}{*}{$L$} & \multicolumn{3}{|c|}{$0^{0} / 90^{0}(G E / K E)$} & \multicolumn{3}{|c|}{$0^{0} / 90^{0}(E G E / K E)$} \\
\hline & $\begin{array}{c}\omega_{1} \\
7.29447\end{array}$ & $\begin{array}{c}\omega_{2} \\
9.93625\end{array}$ & $\begin{array}{c}\omega_{3} \\
12.71320\end{array}$ & $\begin{array}{c}\omega_{1} \\
7.06273\end{array}$ & $\begin{array}{c}\omega_{2} \\
8.60076\end{array}$ & $\begin{array}{c}\omega_{3} \\
11.03650\end{array}$ \\
\hline 1 & 1.28747 & 1.86972 & 2.78669 & 1.27003 & 1.90977 & 2.72980 \\
\hline 1.5 & 0.23862 & 0.70058 & 1.25013 & 0.27338 & 0.73691 & 1.22422 \\
\hline 2 & 0.09704 & 0.63671 & 1.12197 & 0.20645 & 0.57914 & 0.91235 \\
\hline 2.5 & 0.08611 & 0.53729 & 1.05032 & 0.02844 & 0.52499 & 0.85376 \\
\hline
\end{tabular}

TABLE 3: Relation between frequency $\lambda_{m}$ and circumferential node number $n$ of three- and six-layered cylindrical shell $L=1.5$.

\begin{tabular}{cccccc}
\hline$n$ & \multicolumn{3}{c}{$0^{0} / 90^{0} / 0^{0}(G E / K E / G E)$} & \multicolumn{2}{c}{$0^{0} / 90^{0} / 0^{0} / 90^{0} / 0^{0} / 90^{0}(G E / K E / G E / K E / G E / K E)$} \\
\hline 1 & $\lambda_{1}$ & $\lambda_{2}$ & $\lambda_{3}$ & $\lambda_{1}$ & $\lambda_{3}$ \\
3 & 0.00025 & 0.00039 & 0.00049 & 0.00029 & 0.00033 \\
5 & 0.00015 & 0.00022 & 0.00030 & 0.00020 & 0.00026 \\
7 & 0.00011 & 0.00018 & 0.00025 & 0.00018 & 0.00024 \\
9 & 0.00016 & 0.00023 & 0.00032 & 0.00021 & 0.00026 \\
\hline
\end{tabular}

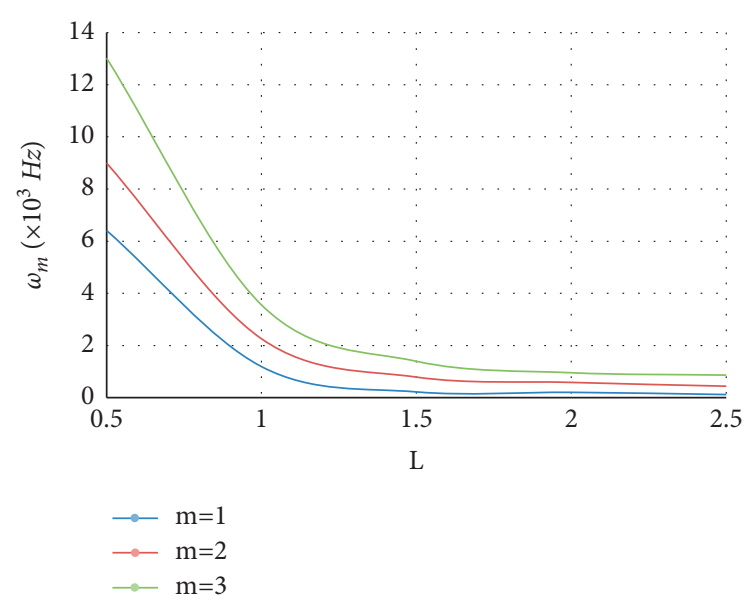

Figure 3: Relation between frequency and length of three-layered shells $0^{0} / 90^{\circ} / 0^{0}(G E / K E / G E) ; n=2$.

length increases, the bending deformation becomes dominant in the system.

Relation between the frequency and circumferential node number of 3 - and 5-layered shells $\left(0^{\circ} / 90^{\circ} / 0^{\circ}\right.$, $\left.0^{0} / 90^{\circ} / 0^{0} / 90^{\circ} / 0^{0}\right)$ with material combinations ( (EGE/KE/EGE), (EGE/KE/EGE/KE/EGE)) and $L=0.5$ is shown in Figures 6 and 7. The frequency value decreases till $n=6$ and gradually increases as the circumferential node number increases. Since the decrease in the frequency shows that the rigidity of the structure decreases till $n=6$ and as the circumferential node number increases, the frequency increases and so the 


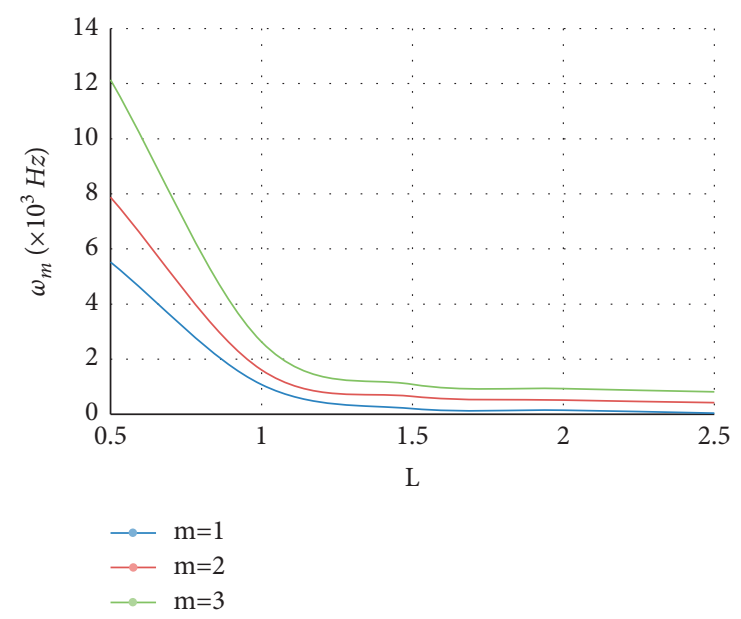

FigURE 4: Relation between frequency and length of four-layered shells $0^{0} / 90^{\circ} / 0^{\circ} / 90^{\circ}(G E / K E / G E / K E) ; n=2$.

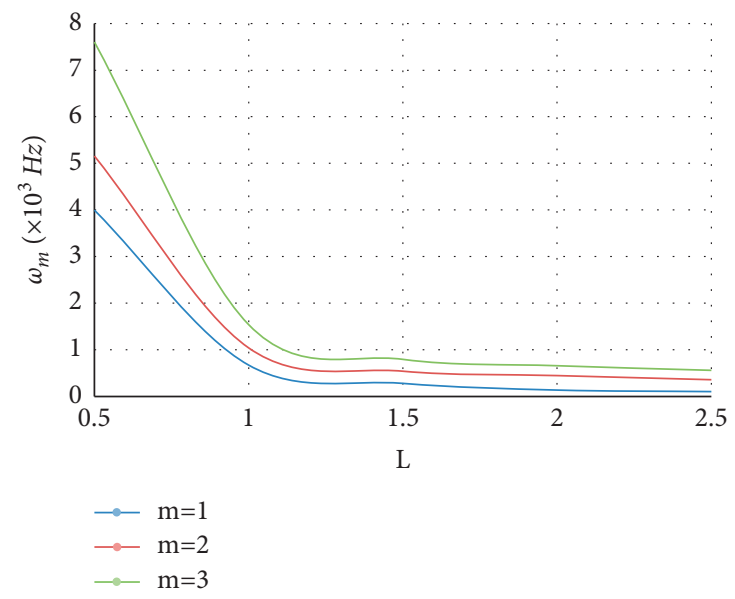

Figure 5: Relation between frequency and length of five-layered shells $0^{\circ} / 90^{\circ} / 0^{\circ} / 90^{\circ} / 0^{0} \quad(E G E / K E / E G E / K E / E G E) ; n=2$.

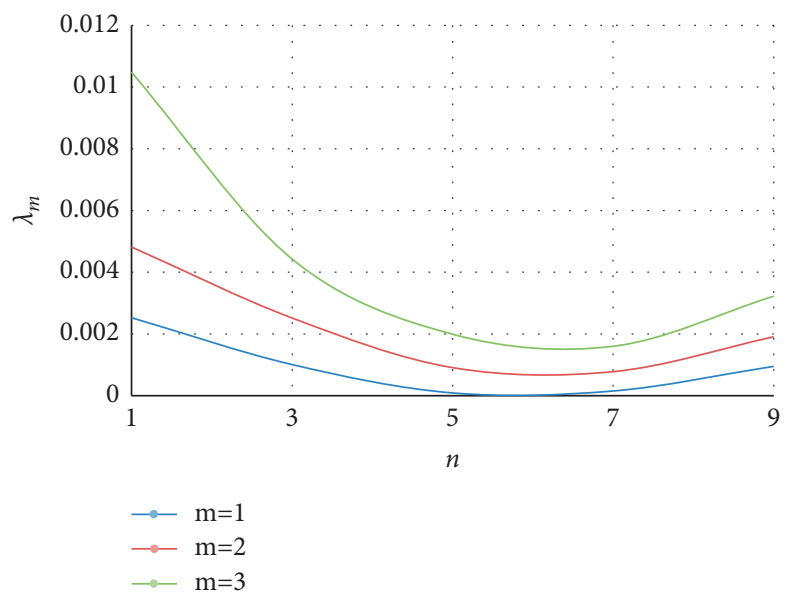

FIGURE 6: Relation between frequency and circumferential node number of three-layered shells $0^{0} / 90^{\circ} / 0^{\circ}(E G E / K E / E G E) ; L=0.5$. 


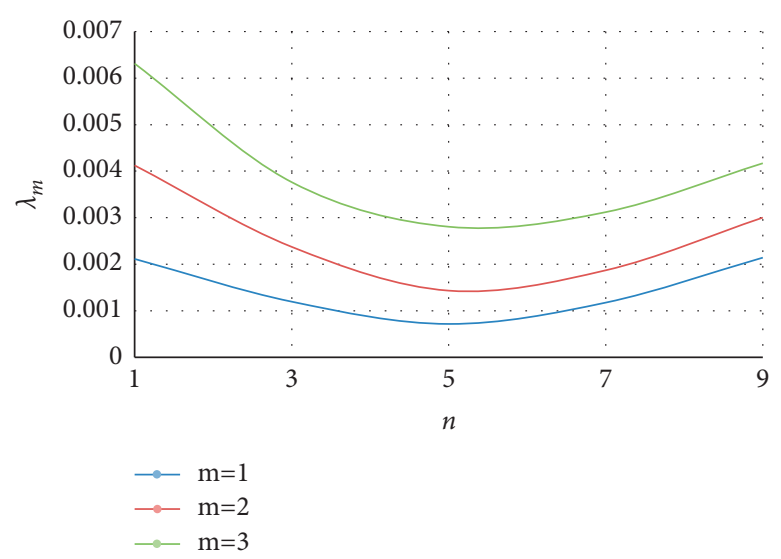

FIGURE 7: Relation between frequency and circumferential node number of five-layered shells $0^{0} / 90^{\circ} / 0^{0} / 90^{\circ} / 0^{0}(E G E / K E / E G E / K E / E G E) ; L=0.5$.

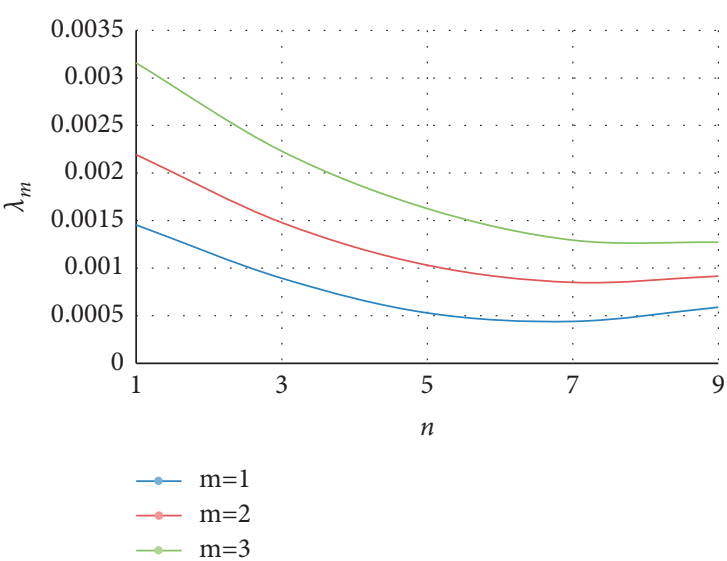

Figure 8: Relation between frequency and circumferential node number of five-layered shells $0^{0} / 90^{\circ} / 0^{0} / 90^{\circ} / 0^{\circ}(\mathrm{GE} / \mathrm{KE} / \mathrm{GE} / \mathrm{KE} / \mathrm{G}$ $E) ; L=0.5$.

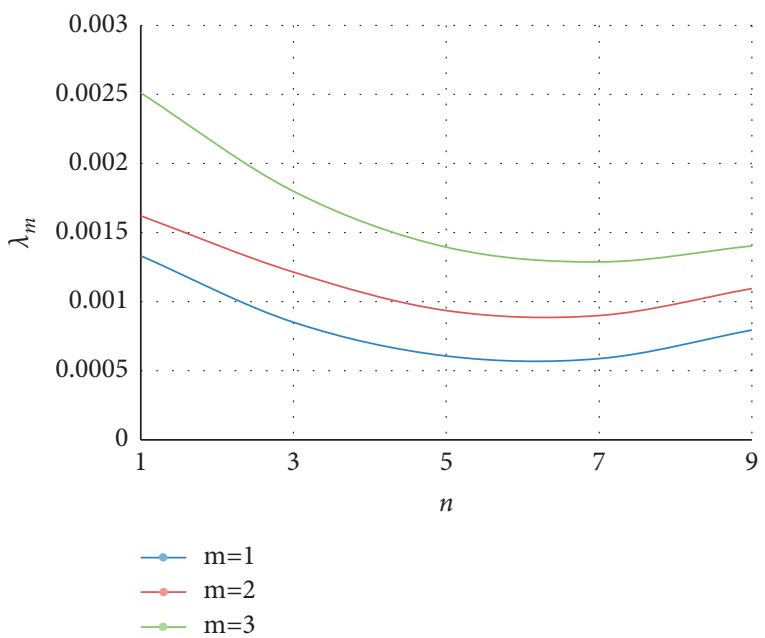

Figure 9: Relation between frequency and circumferential node number of three-layered shells $0^{0} / 90^{\circ} / 0^{\circ}(G E / K E / G E) ; L=0.5$.

rigidity of the structure also increases. It is also evident that as rigidity of the structure increases, its flexibility decreases.

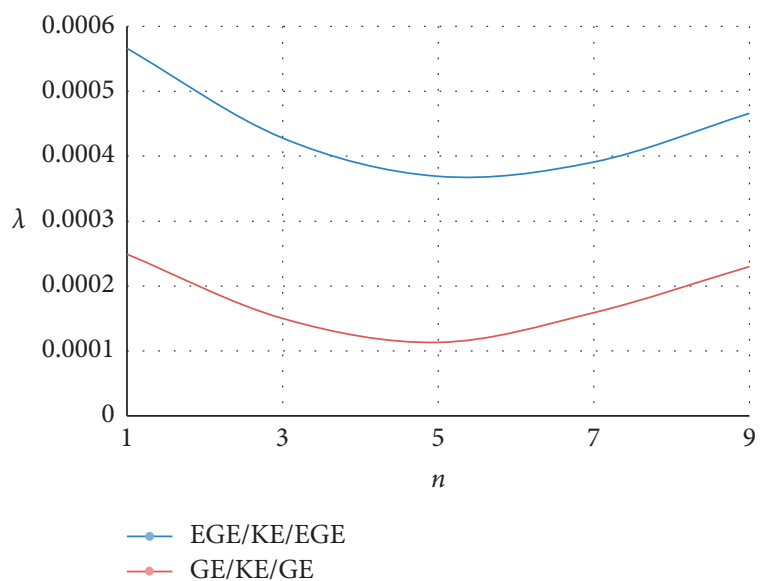

Figure 10: Relation between frequency and circumferential node number of three-layered shells $0^{0} / 90^{\circ} / 0^{0} L=1.5$.

Figures 8 and 9 show the relation between frequency parameter $\lambda_{m}$ and circumferential node number $n$ for 5 - and 3-layered cross-ply cylindrical shells, respectively.

The relation of fundamental frequency $\lambda$ and circumferential node number $n$ of 3-layered cylindrical shells with material orientations $(G E / K E / G E)$ and $(E G E / K E / E G E)$ is shown in Figure 10. The fundamental frequency value is significantly higher for cylindrical shells with material combination (EGE/KE/EGE) than (GE/KE/GE).

\section{Conclusion}

The present investigation explicates the vibrational response of cylindrical shells under HSDT for SS support condition. It is concluded that length, circumferential node number, stacking sequence, number of layers, and their constituents significantly affect the shell analysis. Moreover, the effect of length on the shell's angular frequency parameter is that the membrane longitudinal strain dominates the total strain energy of the system till length of the shell is 1 , and as the length increases, the bending deformation becomes dominant in the system. The effect of the circumferential node number on frequency shows that the frequency value decreases till $n=6$ and gradually increases as the 
circumferential node number increases. The decrease in the frequency value shows that the rigidity of the structure decreases till $n=6$, and as the circumferential node number increases, the frequency increases and so the rigidity of the structure also increases. The comparative study confirms the existing results that may contribute its unique part to already existing research of the related field.

\section{Appendix}

\section{A}

Elements of the transformed stiffness matrix for the material of $k$-th layer are as follows:

$$
\begin{aligned}
& \bar{Q}_{11}^{(k)}=Q_{11}^{(k)} \cos ^{4} \theta+Q_{22}^{(k)} \sin ^{4} \theta+2\left(Q_{22}^{(k)}+2 Q_{66}^{(k)}\right) \sin ^{2} \theta \cos ^{2} \theta \\
& \bar{Q}_{22}^{(k)}=Q_{11}^{(k)} \sin ^{4} \theta+Q_{22}^{(k)} \cos ^{4} \theta+2\left(Q_{12}^{(k)}+2 Q_{66}^{(k)}\right) \sin ^{2} \theta \cos ^{2} \theta \\
& \bar{Q}_{12}^{(k)}=\left(Q_{11}^{(k)}+Q_{22}^{(k)}-Q_{66}^{(k)}\right) \sin ^{2} \theta \cos ^{2} \theta+Q_{12}^{(k)}\left(\cos ^{4} \theta+\sin ^{4} \theta\right), \\
& \bar{Q}_{16}^{(k)}=\left(Q_{11}^{(k)}-Q_{22}^{(k)}-2 Q_{66}^{(k)}\right) \cos ^{3} \theta \sin \theta-\left(Q_{22}^{(k)}-Q_{12}^{(k)}-2 Q_{66}^{(k)}\right) \sin ^{3} \theta \cos \theta, \\
& \bar{Q}_{26}^{(k)}=\left(Q_{11}^{(k)}-Q_{22}^{(k)}-2 Q_{66}^{(k)}\right) \cos ^{3} \theta \sin ^{3} \theta-\left(Q_{22}^{(k)}-Q_{12}^{(k)}-2 Q_{66}^{(k)}\right) \sin ^{3} \theta \cos ^{3} \theta, \\
& \bar{Q}_{66}^{(k)}=\left(Q_{11}^{(k)}+Q_{22}^{(k)}-2 Q_{12}^{(k)}-2 Q_{66}^{(k)}\right) \cos ^{2} \theta \sin ^{2} \theta+Q_{66}^{(k)}\left(\sin ^{4} \theta+\cos ^{4} \theta\right), \\
& \bar{Q}_{44}^{(k)}=Q_{55}^{(k)} \sin ^{2} \theta+Q_{44}^{(k)} \cos ^{2} \theta \\
& \bar{Q}_{55}^{(k)}=Q_{55}^{(k)} \cos ^{2} \theta+Q_{44}^{(k)} \sin ^{2} \theta \\
& \bar{Q}_{45}^{(k)}=\left(Q_{55}^{(k)}-Q_{44}^{(k)}\right) \cos ^{2} \theta \sin ^{2} \theta
\end{aligned}
$$

B

Stiffness coefficients are

$$
\begin{aligned}
A_{i j} & =\sum_{k} \bar{Q}_{i j}^{(k)}\left(z_{k}-z_{k-1}\right), \\
B_{i j} & =\frac{1}{2} \sum_{k} \bar{Q}_{i j}^{(k)}\left(z_{k}^{2}-z_{k-1}^{2}\right), \\
D_{i j} & =\frac{1}{3} \sum_{k} \bar{Q}_{i j}^{(k)}\left(z_{k}^{3}-z_{k-1}^{3}\right), \\
E_{i j} & =\frac{1}{4} \sum_{k} \bar{Q}_{i j}^{(k)}\left(z_{k}^{4}-z_{k-1}^{4}\right), \\
F_{i j} & =\frac{1}{5} \sum_{k} \bar{Q}_{i j}^{(k)}\left(z_{k}^{5}-z_{k-1}^{5}\right), \\
H_{i j} & =\frac{1}{7} \sum_{k} \bar{Q}_{i j}^{(k)}\left(z_{k}^{7}-z_{k-1}^{7}\right), \quad \text { for } i, j=1,2,6, \\
A_{i j}^{\prime} & =\sum_{k} \bar{Q}_{i j}^{(k)}\left(z_{k}-z_{k-1}\right), \\
D_{i j}^{\prime} & =\frac{1}{3} \sum_{k} \bar{Q}_{i j}^{(k)}\left(z_{k}^{3}-z_{k-1}^{3}\right), \\
F_{i j}^{\prime} & =\frac{1}{5} \sum_{k} \bar{Q}_{i j}^{(k)}\left(z_{k}^{5}-z_{k-1}^{5}\right), \quad \text { for } i, j=4,5 .
\end{aligned}
$$


C

$$
\begin{aligned}
& Y_{11}=\frac{\mathrm{d}^{2}}{\mathrm{~d} X^{2}}-s_{10} \frac{n^{2}}{r^{2}}+\lambda^{2} \\
& Y_{12}=\left(s_{2}+s_{10}\right) \frac{n}{r} \frac{\mathrm{d}}{\mathrm{dX}} \\
& Y_{13}=-s_{17} c_{2} \frac{\mathrm{d}^{3}}{\mathrm{~d} X^{3}}+\left(s_{2} \frac{1}{r}+\left(s_{18} c_{2}-2 s_{26}\right) \frac{n^{2}}{r^{2}}\right) \frac{\mathrm{d}}{\mathrm{d} X}-\lambda^{2} p_{5} c_{1} \frac{\mathrm{d}}{\mathrm{d} X}, \\
& Y_{14}=\left(s_{4}-s_{17} c_{2}\right) \frac{\mathrm{d}^{2}}{\mathrm{~d} X^{2}}-\left(s_{11}-s_{26} c_{2}\right) \frac{n^{2}}{r^{2}}+\lambda^{2} p_{4}-\lambda^{2} p_{5} c_{1}, \\
& Y_{15}=\left(s_{5}-s_{18} c_{2}+s_{11}-s_{26} c_{2}\right) \frac{n}{r} \frac{\mathrm{d}}{\mathrm{d} X}, \\
& Y_{21}=-\left(s_{10}+s_{2}\right) \frac{n}{r} \frac{\mathrm{d}}{\mathrm{d} X} \\
& Y_{22}=s_{10} \frac{\mathrm{d}^{2}}{\mathrm{~d} X^{2}}-\left(s_{13}-s_{29} c_{1}\right) \frac{1}{r^{2}}-s_{3} \frac{n^{2}}{r^{2}}+\lambda^{2}+\frac{2}{r} \lambda^{2} p_{4}, \\
& Y_{23}=\left(2 s_{26} c_{2}+s_{18} c_{2}\right) \frac{n}{r} \frac{\mathrm{d}^{2}}{\mathrm{~d} X^{2}}-s_{19} c_{2} \frac{n^{3}}{r^{3}}-\left(s_{3}+s_{13}-s_{29} c_{1}\right) \frac{n}{r^{2}}+\lambda^{2} p_{5} n c_{1}+\frac{1}{r} \lambda^{2} p_{2} n c_{1}, \\
& Y_{24}=-\left(s_{11}-s_{26} c_{2}+s_{5}-s_{18} c_{2}\right) \frac{n}{r} \frac{\mathrm{d}}{\mathrm{d} X}, \\
& Y_{25}=\left(s_{11}-s_{26} c_{2}\right) \frac{\mathrm{d}^{2}}{\mathrm{~d} X^{2}}+\left(s_{13}-s_{29} c_{1}\right) \frac{1}{r}-\left(s_{6}-s_{19} c_{2}\right) \frac{n^{2}}{r^{2}}+\lambda^{2} p_{4}+\frac{1}{r} \lambda^{2} p_{1}-\lambda^{2} p_{5} c_{1}-\frac{1}{r} \lambda^{2} p_{2} c_{1}, \\
& Y_{31}=s_{17} c_{2} \frac{\mathrm{d}^{3}}{\mathrm{~d} X^{3}}-\left(s_{2} \frac{1}{r}+\left(s_{18} c_{2}+2 s_{26} c_{2}\right) \frac{n^{2}}{r^{2}}\right) \frac{\mathrm{d}}{\mathrm{d} X}+\lambda^{2} p_{5} c_{1} \frac{\mathrm{d}}{\mathrm{d} X}, \\
& Y_{32}=\left(s_{18} c_{2}+2 s_{26} c_{2}\right) \frac{n}{r} \frac{\mathrm{d}^{2}}{\mathrm{~d} X^{2}}-s_{19} c_{2} \frac{n^{3}}{r^{3}}-\left(s_{13}-s_{29} c_{1}-s_{29} c_{2}+s_{31} c_{1} c_{2}+s_{3}\right) \frac{n}{r^{2}}+\lambda^{2} p_{5} n c_{1}+\frac{1}{r} \lambda^{2} p_{2} n c_{1}, \\
& Y_{33}=-s_{23} c_{2}^{2} \frac{\mathrm{d}^{4}}{\mathrm{~d} X^{4}}+\left[\left(2 s_{24} c_{2}^{2}+4 s_{28} c_{2}^{2}\right) \frac{n^{2}}{r^{2}}+s_{14}-s_{30} c_{1}-s_{30} c_{2}+s_{32} c_{1} c_{2}+2 s_{18} c_{2} \frac{1}{r}\right] \frac{\mathrm{d}^{2}}{\mathrm{~d} X^{2}} \\
& -\left(s_{13}-s_{29} c_{1}-s_{29} c_{2}+s_{31} c_{1} c_{2}\right) \frac{n^{2}}{r^{2}}-2 s_{19} c_{2} \frac{n^{2}}{r^{3}}+s_{25} c_{2}^{2} \frac{n^{4}}{r^{4}}+s_{3} \frac{1}{r^{2}}-\lambda^{2} p_{3} c_{1}^{2} \frac{\mathrm{d}^{2}}{\mathrm{~d} X^{2}}+\lambda^{2}+\lambda^{2} p_{3} c_{1}^{2} n^{2}, \\
& Y_{34}=\left(s_{20} c_{2}-s_{23} c_{2}^{2}\right) \frac{\mathrm{d}^{3}}{\mathrm{~d} X^{3}}+\left[s_{14}-s_{30} c_{1}-s_{30} c_{2}+s_{32} c_{1} c_{2}-s_{5} \frac{1}{r}+s_{18} c_{2} \frac{1}{r}+\left(s_{24} c_{2}^{2}-s_{21} c_{2}-2 s_{27} c_{2}+2 s_{28} c_{2}^{2}\right) \frac{n^{2}}{r^{2}}\right] \frac{\mathrm{d}}{\mathrm{d} X} \\
& +\left(c_{1} \lambda^{2} p_{2}-c_{1}^{2} \lambda^{2} p_{3}\right) \frac{\mathrm{d}}{\mathrm{d} X} \\
& Y_{35}=\left(s_{21} c_{2}-s_{24} c_{2}^{2}+2 s_{27} c_{2}-2 s_{28} c_{2}^{2}\right) \frac{n}{r} \frac{\mathrm{d}^{2}}{\mathrm{~d} X^{2}}-\left(s_{22} c_{2}-s_{25} c_{2}^{2}\right) \frac{n^{3}}{r^{3}}+\left(s_{13}-s_{29} c_{1}-s_{29} c_{2}+s_{31} c_{1} c_{2}\right) \frac{n}{r}-\left(s_{6}-s_{19} c_{2}\right) \frac{n}{r^{2}} \\
& +c_{1} \lambda^{2} p_{2} n-c_{1}^{2} \lambda^{2} p_{3} n
\end{aligned}
$$




$$
\begin{aligned}
Y_{41}= & \left(s_{4}-s_{17} c_{1}\right) \frac{\mathrm{d}^{2}}{\mathrm{~d} X^{2}}-\left(s_{11}-s_{26} c_{1}\right) \frac{n^{2}}{r^{2}}+\lambda^{2} p_{4}-\lambda^{2} p_{5} c_{1} \\
Y_{42}= & \left(s_{5}-s_{18} c_{1}+s_{11}-s_{26} c_{1}\right) \frac{n}{r} \frac{\mathrm{d}}{\mathrm{d} X} \\
Y_{43}= & \left(s_{23} c_{1} c_{2}-s_{20} c_{2}\right) \frac{\mathrm{d}^{3}}{\mathrm{~d} X^{3}}+\left[\left(s_{5}-s_{18} c_{1}\right) \frac{1}{r}-\left(s_{14}-s_{30} c_{1}-s_{30} c_{2}+s_{32} c_{1} c_{2}\right)+\left(s_{21} c_{2}-s_{24} c_{1} c_{2}\right) \frac{n^{2}}{r^{2}}+2\left(s_{27} c_{2}-s_{28} c_{1} c_{2}\right) \frac{n^{2}}{r^{2}}\right] \\
& \frac{\mathrm{d}}{\mathrm{d} X}-\left(\lambda^{2} p_{2} c_{1}-\lambda^{2} p_{3} c_{1}^{2}\right) \frac{\mathrm{d}}{\mathrm{d} X},
\end{aligned}
$$

$$
\begin{aligned}
Y_{44}= & \left(s_{7}-s_{20} c_{2}-s_{20} c_{1}+s_{23} c_{1} c_{2}\right) \frac{\mathrm{d}^{2}}{\mathrm{~d} X^{2}}-\left(s_{12}-s_{27} c_{2}-s_{27} c_{1}+s_{28} c_{1} c_{2}\right) \frac{n^{2}}{r^{2}}-\left(s_{14}-s_{30} c_{1}+s_{30} c_{2}+s_{32} c_{1} c_{2}\right) \\
& +\left(\lambda^{2} p_{1}-2 \lambda^{2} p_{2} c_{1}+\lambda^{2} p_{3} c_{1}^{2}\right)
\end{aligned}
$$$$
Y_{45}=\left(s_{8}-s_{21} c_{2}-s_{21} c_{1}+s_{24} c_{1} c_{2}+s_{12}-s_{27} c_{2}-s_{27} c_{1}+s_{28} c_{1} c_{2}\right) \frac{n}{r} \frac{\mathrm{d}}{\mathrm{dX}},
$$

$$
Y_{51}=-\left(s_{11}-s_{26} c_{1}+s_{5}-s_{18} c_{1}\right) \frac{n}{r} \frac{\mathrm{d}}{\mathrm{d} X}
$$$$
Y_{52}=\left(s_{11}-s_{26} c_{1}\right) \frac{\mathrm{d}^{2}}{\mathrm{~d} X^{2}}-\left(s_{6}-s_{19} c_{1}\right) \frac{n^{2}}{r^{2}}+\left(s_{13}-s_{29} c_{1}-s_{29} c_{2}+s_{31} c_{1} c_{2}\right) \frac{1}{r}+\lambda^{2} p_{4}+\frac{1}{r} \lambda^{2} p_{1}-\lambda^{2} p_{5} c_{1}-\frac{1}{r} \lambda^{2} p_{2} c_{1},
$$

$$
\begin{aligned}
Y_{53}= & \left(2 s_{27} c_{2}-2 s_{28} c_{1} c_{2}+s_{21} c_{2}-s_{24} c_{1} c_{2}\right) \frac{n}{r} \frac{\mathrm{d}^{2}}{\mathrm{~d} X^{2}}-\left(s_{22} c_{2}-s_{25} c_{1} c_{2}\right) \frac{n^{3}}{r^{3}}-\left(s_{6}-s_{18} c_{1}\right) \frac{1}{r^{2}}+\left(s_{13}-s_{29} c_{1}-s_{29} c_{2}+s_{31} c_{1} c_{2}\right) \frac{1}{r} \\
& +\left(c_{1} \lambda^{2} p_{2}-c_{1}^{2} \lambda^{2} p_{3}\right) n,
\end{aligned}
$$

$$
\begin{aligned}
Y_{54}= & -\left(s_{12}-s_{27} c_{1}-s_{27} c_{2}+s_{28} c_{1} c_{2}+s_{8}-s_{21} c_{1}--s_{21} c_{2}+s_{24} c_{1} c_{2}\right) \frac{n}{r} \frac{\mathrm{d}}{\mathrm{d} X}, \\
Y_{55}= & \left(s_{12}-s_{27} c_{1}-s_{27} c_{2}+s_{28} c_{1} c_{2}\right) \frac{\mathrm{d}^{2}}{\mathrm{~d} X^{2}}-\left(s_{13}-s_{29} c_{1}-s_{29} c_{2}+s_{31} c_{1} c_{2}\right)-\left(s_{9}-s_{22} c_{2}-s_{22} c_{1}+s_{25} c_{1} c_{2}\right) \frac{n^{2}}{r^{2}} \\
& +\left(\lambda^{2} p_{1}-2 c_{1} \lambda^{2} p_{2}+c_{1}^{2} \lambda^{2} p_{3}\right),
\end{aligned}
$$

where

$$
\begin{aligned}
& \lambda^{2}=\frac{I_{0} \omega^{2} \ell^{2}}{A_{11}}, \\
& p_{1}=\frac{I_{2}}{I_{0} \ell^{2}}, p_{2}=\frac{I_{4}}{I_{0} \ell^{2}}, p_{3}=\frac{I_{6}}{I_{0} \ell^{2}}, p_{4}=\frac{I_{1}}{I_{0} \ell^{2}}, p_{5}=\frac{I_{3}}{I_{0} \ell^{2}}, \\
& s_{2}=\frac{A_{12}}{A_{11}}, s_{3}=\frac{A_{22}}{A_{11}}, s_{4}=\frac{B_{11}}{\ell A_{11}}, s_{5}=\frac{B_{12}}{\ell A_{11}}, s_{6}=\frac{B_{22}}{\ell A_{11}} s_{7}=\frac{D_{11}}{\ell^{2} A_{11}}, s_{8}=\frac{D_{12}}{\ell^{2} A_{11}}, s_{9}=\frac{D_{22}}{\ell^{2} A_{11}}, \\
& s_{10}=\frac{A_{66}}{A_{11}}, s_{11}=\frac{B_{66}}{\ell A_{11}}, s_{12}=\frac{D_{66}}{\ell^{2} A_{11}}, s_{13}=\frac{A_{44}}{A_{11}}, s_{14}=\frac{A_{55}}{A_{11}}, s_{15}=\frac{B_{16}}{\ell A_{11}}, s_{16}=\frac{B_{26}}{\ell A_{11}}, s_{17}=\frac{E_{11}}{\ell^{3} A_{11}},
\end{aligned}
$$




$$
\begin{aligned}
& s_{18}=\frac{E_{12}}{\ell^{3} A_{11}}, s_{19}=\frac{E_{22}}{\ell^{3} A_{11}}, s_{20}=\frac{F_{11}}{\ell^{4} A_{11}}, s_{21}=\frac{F_{12}}{\ell^{4} A_{11}}, s_{22}=\frac{F_{22}}{\ell^{4} A_{11}}, s_{23}=\frac{H_{11}}{\ell^{6} A_{11}}, s_{24}=\frac{H_{12}}{\ell^{6} A_{11}}, \\
& s_{25}=\frac{H_{22}}{\ell^{6} A_{11}}, s_{26}=\frac{E_{66}}{\ell^{3} A_{11}}, s_{27}=\frac{F_{66}}{\ell^{4} A_{11}}, s_{28}=\frac{H_{66}}{\ell^{6} A_{11}}, s_{29}=\frac{D_{44}}{\ell^{2} A_{11}}, s_{30}=\frac{D_{55}}{\ell^{2} A_{11}}, s_{31}=\frac{F_{44}}{\ell^{4} A_{11}}, \\
& s_{32}=\frac{F_{55}}{\ell^{4} A_{11}}, s_{33}=\frac{E_{16}}{\ell^{3} A_{11}}, s_{34}=\frac{E_{26}}{\ell^{3} A_{11}}, s_{35}=\frac{F_{16}}{\ell^{4} A_{11}}, s_{36}=\frac{F_{26}}{\ell^{4} A_{11}}, s_{37}=\frac{H_{16}}{\ell^{6} A_{11}}, s_{38}=\frac{H_{26}}{\ell^{6} A_{11}} .
\end{aligned}
$$

\section{Data Availability}

The data supporting the results of this study are included in the manuscript.

\section{Conflicts of Interest}

The authors declare that they have no conflicts of interest regarding the publication of this paper.

\section{Acknowledgments}

The authors gratefully acknowledge the Deanship of Scientific Research at King Faisal University Saudi Arabia for the financial support under Nasher Track (Grant no. 216029).

\section{References}

[1] M. R. Zarastvand, M. Ghassabi, and R. Talebitooti, "Acoustic nsulation characteristics of shell structures: a review," $A r$ chives of Computational Methods n Engineering, pp. 1-19, 2019.

[2] R. Talebitooti, H. D. Gohari, and M. R. Zarastvand, "Multi objective optimization of sound transmission across laminated composite cylindrical shell lined with porous core investigating Non-dominated Sorting Genetic Algorithm," Aerospace Science and Technology, vol. 69, pp. 269-280, 2017.

[3] H. Darvishgohari, M. Zarastvand, R. Talebitooti, and R. Shahbazi, "Hybrid control technique for vibroacoustic performance analysis of a smart doubly curved sandwich structure considering sensor and actuator layers," Journal of Sandwich Structures and Materials, vol. 23, no. 5, pp. 14531480, 2021.

[4] R. Talebitooti, M. Zarastvand, and H. Gohari, "Investigation of power transmission across laminated composite doubly curved shell in the presence of external flow considering shear deformation shallow shell theory," Journal of Vibration and Control, vol. 24, no. 19, pp. 4492-4504, 2018.

[5] K. Rahmatnezhad, M. R. Zarastvand, and R. Talebitooti, "Mechanism study and power transmission feature of acoustically stimulated and thermally loaded composite shell structures with double curvature," Composite Structures, vol. 276, p. 114557, 2021.

[6] R. Talebitooti, M. R. Zarastvand, and M. R. Gheibi, "Acoustic transmission through laminated composite cylindrical shell employing Third order Shear Deformation Theory in the presence of subsonic flow," Composite Structures, vol. 157, pp. 95-110, 2016.

[7] H. Darvish Gohari, M. Zarastvand, and R. Talebitooti, "Acoustic performance prediction of a multilayered finite cylinder equipped with porous foam media," Journal of $\mathrm{Vi}$ bration and Control, vol. 26, no. 11-12, pp. 899-912, 2020.

[8] R. Talebitooti and M. R. Zarastvand, "The effect of nature of porous material on diffuse field acoustic transmission of the sandwich aerospace composite doubly curved shell," Aerospace Science and Technology, vol. 78, pp. 157-170, 2018.

[9] R. Talebitooti, M. R. Zarastvand, and H. D. Gohari, "The influence of boundaries on sound insulation of the multilayered aerospace poroelastic composite structure," Aerospace Science and Technology, vol. 80, pp. 452-471, 2018.

[10] A. E. H. Love, A Treatise on the Mathematical Theory of Elasticity, Cambrige UniversityPress, New York, NY, USA, 1st edition, 1892.

[11] P. M. Naghdi, "Foundations of elastic shell theory," in Progress and Solid Mechanics, N. Sneddon, Ed., Vol. 4, North-Holland Publishing Company, Amsterdam, Netherlands, 1963.

[12] J. N. Reddy, "iA simple higher-order theory for laminated composite plates," Journal of Applied Mechanics, vol. 51, pp. i745-752, 1984.

[13] J. N. Reddy and C. F. Liu, "A higher-order shear deformation theory of laminated elastic shells," International Journal of Engineering Science, vol. 23, no. 3, pp. 319-330, 1985.

[14] J. R. Vinson, "Sandwich structures," Applied Mechanics Reviews, vol. 54, no. 3, pp. 201-214, 2001.

[15] A. K. Noor, W. S. Burton, and C. W. Bert, "Computational models for sandwich panels and shells," Applied Mechanics Reviews, vol. 49, no. 3, pp. 155-199, 1996.

[16] J. N. Reddy, Theory and Analysis of Elastic Pates and Shells, CRC Press, Boca Raton, FL, USA, 2006.

[17] A. Baghlani, M. Khayat, and S. M. Dehghan, "Free vibration analysis of FGM cylindrical shells surrounded by pasternak elastic foundation in thermal environment considering fluidstructure interaction," Applied Mathematical Modelling, vol. 78, pp. 550-575, 2020.

[18] M. L. Dehsaraji, M. Arefi, and A. Loghman, "Size dependent free vibration analysis of functionally graded piezoelectric micro/nano shell based on modified couple stress theory with considering thickness stretching effect," Defence Technology, 2020.

[19] A. S. Sayyad and Y. M. Ghugal, "Static and free vibration analysis of laminated composite and sandwich spherical shells using a generalized higher-order shell theory," Composite Structures, vol. 219, pp. 129-146, 2019.

[20] M. Rout, S. S. Hota, and A. Karmakar, "Thermoelastic free vibration response of graphene reinforced laminated composite shells," Engineering Structures, vol. 178, pp. 179-190, 2019.

[21] A. Zine, A. Tounsi, K. Draiche, I. M. Sekkal, and S. R. A. Mahmoud, "Novel higher-order shear deformation theory for bending and free vibration analysis of isotropic and multilayered plates and shells," Steel and Composite Structures, vol. 26, no. 2, pp. 125-137, 2018. 
[22] D. Chavan, D. Chavan, B. Nikam, M. Kale, V. Jamale, and S. Chavan, "Efficacy of $800 \mathrm{~nm}$ diode laser to treat trichostasis spinulosa in Asian patients," International Journal of Trichology, vol. 10, no. 1, pp. 21-49, 2018.

[23] S. Zghal, A. Frikha, and F. Dammak, "Free vibration analysis of carbon nanotube-reinforced functionally graded composite shell structures," Applied Mathematical Modelling, vol. 53, pp. 132-155, 2018.

[24] C. K. Hirwani, T. R. Mahapatra, S. K. Panda, S. S. Sahoo, V. K. Singh, and B. K. Patle, "Nonlinear free vibration analysis of laminated carbon/epoxy curved panels," Defence Science Journal, vol. 67, no. 2, p. 207, 2017.

[25] A. Shenas, G. P. Malekzadeh, and S. Ziaee, "Vibration analysis of pre-twisted functionally graded carbon nanotube reinforced composite beams in thermal environment," Composite Structures, vol. 162, pp. 325-340, 2017.

[26] A. R. Setoodeh, M. Shojaee, and P. Malekzadeh, "Application of transformed differential quadrature to free vibration analysis of FG-CNTRC quadrilateral spherical panel with piezoelectric layers," Computer Methods in Applied Mechanics and Engineering, vol. 335, pp. 510-537, 2018.

[27] N. Sharma, T. R. Mahapatra, S. K. Panda, and C. K. Hirwani, "Acoustic radiation and frequency response of higher-order shear deformable multilayered composite doubly curved shell panel - an experimental validation," Applied Acoustics, vol. 133, pp. 38-51, 2018.

[28] H. Ersoy, K. Mercan, and Ö. Civalek, "Frequencies of FGM shells and annular plates by the methods of discrete singular convolution and differential quadrature methods," Composite Structures, vol. 183, pp. 7-20, 2018.

[29] D. Punera and T. Kant, "Elastostatics of laminated and functionally graded sandwich cylindrical shells with two refined higher order models," Composite Structures, vol. 182, pp. 505-523, 2017.

[30] C. Hwu, H. W. Hsu, and Y. H. Lin, "Free vibration of composite sandwich plates and cylindrical shells," Composite Structures, vol. 171, pp. 528-537, 2017.

[31] Nasihatgozar, M. Khalili, and I. R. K. M. Fard, "General equations for free vibrations of thick doubly curved sandwich panels with compressible and incompressible core using higher order shear deformation theory," Steel and Composite Structures, vol. 24, no. 2, pp. 151-176, 2017.

[32] T.-K. Nguyen, H.-T. Thai, and P. V. Thuc, "A novel general higher-order shear deformation theory for static, vibration and thermal buckling analysis of the functionally graded plates," Journal of Thermal Stresses, pp. 1-21, 2020.

[33] A. A. Daikh, A. Drai, Bensaid, M. S. A. Houari, and A. Tounsi, "On vibration of functionally graded sandwich nanoplates," Journal of Sandwich Structures and Materials, p. 1099636220909790, 2020.

[34] A. Baghlani, M. Khayat, and S. M. Dehghan, "Free vibration analysis of FGM cylindrical shells surrounded by pasternak elastic foundation in thermal environment considering fluidstructure interaction," Applied Mathematical Modelling, vol. 78, pp. 550-575, 2020.

[35] R. Katili, "On static and free vibration analysis of FGM plates using an efficient quadrilateral finite element based on DSPM," Composite Structures, p. 113514, 2020.

[36] Dhari and R. Singh, "A numerical study on cross ply laminates subjected to stray fragments impact loading," Composite Structures, vol. 261, p. 113563, 2021.

[37] M. Li, R. Yan, L. Xu, and C. Guedes Soares, "A general framework of higher-order shear deformation theories with a novel unified plate model for composite laminated and FGM plates," Composite Structures, vol. 261, p. 113560, 2021.

[38] S. I. Tahir, A. Chikh, A. Tounsi, M. A. Al-Osta, S. U. AlDulaijan, and M. M. Al-Zahrani, "Wave propagation analysis of a ceramic-metal functionally graded sandwich plate with different porosity distributions in a hygro-thermal environment," Composite Structures, vol. 269, p. 114030, 2021.

[39] I. M. Mudhaffar, A. Tounsi, A. Chikh, M. A. Al-Osta, M. M. Al-Zahrani, and S. U. Al-Dulaijan, "Hygro-thermomechanical bending behavior of advanced functionally graded ceramic metal plate resting on a viscoelastic foundation," Structures, vol. 33, pp. 2177-2189, 2021.

[40] D. Kouider, A. Kaci, M. M. Selim et al., "An original fourvariable quasi-3D shear deformation theory for the static and free vibration analysis of new type of sandwich plates with both FG face sheets and FGM hard core," Steel and Composite Structures, vol. 41, no. 2, pp. 167-191, 2021.

[41] B. Merazka, A. Bouhadra, A. Menasria et al., "Hygro-thermomechanical bending response of FG plates resting on elastic foundations," Steel and Composite Structures, vol. 39, no. 5, pp. 631-643, 2021.

[42] H. Hachemi, A. A. Bousahla, A. Kaci et al., "Bending analysis of functionally graded plates using a new refined quasi-3D shear deformation theory and the concept of the neutral surface position," Steel and Composite Structures, vol. 39, no. 1, pp. 51-64, 2021.

[43] S. Javed, K. K. Viswanathan, M. D. Nurul Izyan, Z. A. Aziz, and J. H. Lee, "Free vibration of cross-ply angle-ply laminated plates based on higher order shear theory," Steel and Composite Structures, vol. 22, no. 6, pp. 1281-1299, 2018.

[44] S. Javed, "Free vibration characteristic of laminated conical shells based on higher-order shear deformation theory," Composite Structures, vol. 204, pp. 80-87, 2018.

[45] R. K. Khare, T. Kant, and A. K. Garg, "Free vibration of composite and sandwich laminates with a higher-order facet shell element," Composite Structures, vol. 65, no. 3-4, pp. 405-418, 2004.

[46] A. Bhimaraddi, "Free vibration analysis of doubly curved shallow shells on rectangular planform using three-dimensional elasticity theory," International Journal of Solids and Structures, vol. 27, no. 7, pp. 897-913, 1991. 